\title{
APPENDIX
}

\section{Classification of Lines}

The running lines of British Railways are classified according to their importance and the type, weight, and speed of the traffic which they carry, in accordance with the ruling of the Railway Executive shown in Table 8.

TABLe 8,-Definition of classes of line

\begin{tabular}{c|c}
\hline Class of Line & \multicolumn{1}{c}{ Definition } \\
\hline $\mathrm{A}$ & $\begin{array}{l}\text { Lines subject to speeds exceeding } 60 \text { miles per hour, over which } \\
\text { twelve or more express passenger-trains operate regularly (winter } \\
\text { timetable) per } 24 \text { hours. } \\
\text { Lines subject to speeds of } 60 \text { miles per hour and over, but not } \\
\text { qualified to be classed as A lines. } \\
\text { Lines carrying intensive traffic even though the speed is less than } \\
60 \text { miles per hour. } \\
\text { Lines subject to maximum speeds of } 45 \text { to } 60 \text { miles per hour. } \\
\text { Lines subject to speeds of less than } 45 \text { miles per hour. }\end{array}$ \\
\hline
\end{tabular}

Note: A limited mileage of lines is classified for reasons other than speed and/or traffic density ; for example, high axle-loads of locomotives or other special uses.

The permanent-way material used is graded in accordance with the classification of the line. New material is used on $A$ and $B$ lines, the rails being of the standard flat bottom section weighing $109 \mathrm{lb}$. per yard, or of the former standard bull-head section weighing $95 \mathrm{lb}$. per yard. On class $\mathrm{C}$ lines the rails are either of the standard flat-bottom section weighing $98 \mathrm{lb}$. per yard, or second-hand rails with equivalent life; the other material is new. On class $D$ lines the whole of the material is second-hand, the rails being of slightly lighter weight than those used in C lines.

\section{Discussion}

The Authors introduced the Paper with the aid of a series of lantern slides.

The Chairman said that both the Authors were steeped in the subject with which they had been dealing, and it must have been comparatively simple for them to produce the Paper, because they were thinking about the subject all day long and could easily put on paper exactly what they knew. To one who was perhaps not so familiar as he had been a year ago with those matters, it seemed very simple to look at the charts which had been given, and he did not agree with $\mathrm{Mr}$ Maycock that they were complicated; they seemed to be extraordinarily simple, but whether they were quite so simple as they seemed would no doubt be made clear in the subsequent discussion. The subject was a most important one to British 
Railways, and the Paper and discussion should be of value not only in Great Britain but overseas; there were people abroad who still looked to the mother country for a lead in such matters.

Mr J. Taylor Thompson said that the subject of the Paper had occupied the attention of railway engineers the world over for very many years. In Great Britain it had become of special interest in about the year 1935, when high-speed trains had started to run on both the East Coast and the West Coast main lines. A speed of 126 miles per hour had been achieved, and it had been obvious that very high speeds were going to be attained in normal running. The result of that was that the range of speeds increased enormously, from the slow freight train at perhaps 25 to 35 miles per hour up to approximately 100 miles per hour. The range to be catered for in curves and cant became, therefore, a matter of very great consequence. Incidentally, that showed the importance of reducing the range of speed on railways, in order to increase the capacity of the lines as well as to simplify the position from the point of view of the civil engineer, with regard both to maintenance and to the question of speed on curves.

The problem as it had appeared in 1935, and had been discussed at very many meetings at about that time, had been that of cant deficiency; that became the crux of all the discussions. The point was that it was not practicable to cant a curve for the highest speeds attainable, especially in view of the low speeds of some of the traffic, which would result in a very high weight on the low rail if the track was canted for the highest speed. The problem, therefore, was how much higher could the maximum speed be than the speed for which the cant was provided.

In 1938 he had become particularly interested in the subject, and had written a Paper which was mentioned by the present Authors. In connexion with that, he had arranged some tests, though they had not been nearly so elaborate as those described by the Authors. Mr Graff-Baker, of the underground railways, had arranged to carry out some tests on underground stock, because it had appeared that a passenger sitting on a longitudinal seat in an underground train subject to braking was subjected to much the same sensation as a passenger on a train going round a curve, having that feeling inside him which created discomfort, and comfort was really the crux of the matter; comfort was under discussion, not safety.

Mr Taylor Thompson therefore had had those tests made on the underground railways, which corresponded very much with what was said in the present Paper. In addition, he happened to know a bridge structural contractor who, as a side-line, ran a merry-go-round at a holiday resort, and he had found out from him how fast it was possible to swing people round before they felt a similar sensation. Putting those two rather elementary tests together, the track tests and the merry-go-round, $\mathbf{M r}$ Taylor Thompson had arrived at a cant deficiency of $4 \frac{3}{4}$ inches. He had therefore been very interested to see that the results of the much more elaborate tests made by the present Authors had finally produced, with a 
fair margin of safety, a cant deficiency of $3 \frac{1}{2}$ inches. He could easily accept that lower figure.

As soon as nationalization of the railways had taken place, the problem had arisen, of course, of providing a common standard for the railways. He had happened at the time to be Chairman of the Track Committee, to which the subject had been remitted, so that he had a particular interest in the Paper, and he had been one of the people who had taken part in the sensation tests.

It had been of great interest to him to see in the Paper for the first time - he had handed over the Track Committee to Mr Everard before the work was over-that the sensations recorded could be plotted on not too bad a straight-line curve. It was extremely difficult to record a sensation which lasted only for a very short time-1 or $1 \frac{1}{2}$ second-and where it was necessary to determine as between 0 and 6 what the particular sensation was, in that very small space of time. However, it should be said that the tests had provided a very good foundation indeed, and so far as he knew the Paper contained the results of the most elaborate research into the subject which had been published anywhere in the world. As Chairman of the Committee which had arranged the tests, he expressed his own special thanks to both Authors. He agreed with the Chairman that the Paper, and especially the graphs, would be found to be of use all over the world, and particularly in the Colonies and on other railways of full gauge, where no doubt the results would be used as a standard.

Mr Keith Brinsmead said that the trials were of particular interest, because they were the first in which emphasis had been put on comfort. In the past, people had always worried whether it was safe, either for the train or for the track to go at a certain speed, but the tests had proved quite definitely that the discomfort of passengers came into play first.

He thought that there had been a great deal of confusion about cant deficiency. People were inclined-he had been himself-to feel that it was eating into the margin of safety, rather like overloading a bridge; but a train could go off the line only for three reasons. It could overturn, which was a phenomenal feat; it could climb over the high rail on a curve; or the track could give way. It could climb over the high rail on a curve only when the vertical load on the outer rail was too low to resist the lateral thrust, and therefore a little cant deficiency, given good track, actually contributed to safety. That was something which he had only gradually realized.

To decide what was comfortable was an exceedingly difficult thing to do. The personal feelings of the individual came into it. All those taking part in the trials had said, in the course of conversation, "I bet so-and-so will mark one sensation higher than we do," and he had done so. It went to show that it was possible to get considerable variations in trying to decide what was and what was not a reasonable speed at which to go. In Mr Loach's part of the Paper it was very clear from Figs 6 and 7 that 
sensation 5 was obtained at something more than 7 inches cant deficiency on a well-aligned curve, and the same sensation at just over 4 inches on an irregular curve.

The final reduced figures used were, $\mathrm{Mr}$ Brinsmead thought, very logical. They allowed for all the imperfections which must creep in and particularly for the risk on, say, class " $C$ " and class " $D$ " lines, where second-hand materials were used. He could well remember that during the trials, on a curve which had, he thought, the worst cant deficiency, he had not been worried about stability but had said to himself " Those poor fastenings!" He had been able to think of what was happening to the track, but had not been at all worried about the performance of the train.

On p. 518, Mr Loach had referred to the fact that a quickly applied and released lurch did not worry people; the sensations were marked lower than would otherwise have been the case. People might be annoyed by a sudden jolt but would not be alarmed by it if, by the time that they came to think about it, the jolt had gone. They did become annoyed, however, and that was a problem which particularly applied in the case of switchand-crossing work. On the lines of London Transport in particular that problem existed with old tracks, designed a long time ago, with far sharper turnouts than was desirable, and, what was worse, when people were standing at one end of a coach, over a bogie.

He would quote the results of a slight modification to a junction. On the District Railway, running eastwards, just before Whitechapel there was a very sharp bend to the left, and then to the right again. The old original line which ran through to the East London Railway was no longer in use, and, owing to tunnel limitations, there was a situation where they had to get 350 trains a day on each track over " B" switches and 1 in 8 turnouts. Until 10 years ago those switches had been perfectly normal undercut " B " switches, which meant that the train suddenly hit a 1 in 32 angle, which became a serious matter not only for the passengers but also for the wear and tear of the track. The switches at that junction had required renewal approximately once every 12 months. In 1942 there had been substituted some straight-cut curved switches, still " B " switches, but made 4 feet longer, and instead of being straight they were given a radius leading round almost parallel with the running rail. The result of that reduced the angle at which the wheel actually hit the switch-rail to about 1 in 76, and 3 weeks ago the third set of switches to be put in in 10 years had been installed. It would be seen; therefore, that a lot could be done to get rid of small imperfections.

Mr H. C. Orchard observed that the Paper was of particular interest to him because he had been a member of the Track Committee at the time that the tests had been carried out in North Wales. He agreed with all that Mr Taylor Thompson had said about those tests, but had had to leave the Committee before its deliberations on the subject had been completed. 
In the main he was in agreement with the conclusions reached by the Committee.

He thought Mr Loach's part of the Paper showed very clearly the difficulty of the subject, based as it was very largely on sensations rather than mathematics. He thought that if it had been only a question of mathematics, Mr Loach would have found a solution in that direction. The five factors to be established were shown on p. 505. The first, the maximum permissible cant, was largely a matter of judgement-he said " largely" because of cants greater than 6 inches in other parts of the world. The second, third, and fourth were based on personal sensations, and only the last, the steepest permissible cant gradient, would appear to be capable of being checked by physical methods.

With regard to the variable cant deficiency, as a member of the former L.N.E.R. staff Mr Orchard was familiar with its application, but he still had some doubt about whether there should be a different maximum deficiency for classes "A " and "B" lines on the one hand and classes " C" and "D" lines on the other. Apart from the complication which that involved, in the recently-published rules for speeds of trains on curves the differences in the calculated speeds were comparatively small. On 60-chain curves, for instance, where the actual cants were 1 inch, 2 inches, 3 inches, and 4 inches, the differences in the maximum permissible speeds in the higher ranges were $8 \frac{1}{2}, 7 \frac{1}{4}, 6 \frac{3}{4}$, and $6 \frac{1}{4}$ miles per hour respectively. It could be argued that by reason of the heavier manning and consequent higher standard of maintenance and the better material on the "A" and "B" lines they were more capable of withstanding additional side thrust, but he would suggest that renewals on those " $A$ " and " $B$ " lines, when they became due, were often as much attributable to the condition of timber and fastenings just as to that of the rails, and therefore they did form a weak link in the chain of the track.

A further point in that connexion was that there was at least one class "A " line on British Railways which was so tortuous in its route that it was a matter of some difficulty to introduce transitions of desirable length between reverse curves. A maximum cant deficiency of $2 \frac{1}{2}$ inches for all classes of line would help in that respect where existing cants were small.

It was a pity that the minimum cant gradient had been fixed at 1 in 300 and not related to rail length. It was much easier for gangers to remember terms such as 2 inches or 1 inch in a rail length than to remember something like 1 in 25, which was a figure which was strange to them. From that point of view 1 in 360 might have been a better figure. It was appreciated that where that steepest cant gradient was called for, the curve would be monumented, but if the monuments should be displaced the gangers must be relied on to maintain the correct cants until the monuments could be replaced.

Why had it been decided to make the desirable length of a transition $1 \frac{1}{2}$ times the permissible minimum length? By inference the Paper 
emphasized the importance of a high standard of maintenance on transition curves which, because of the site limitations, were shorter than the desirable length. That might well constitute an additional factor for assessing manpower on lengths where there were many such curves and where the formation was poor.

Mr I. G. B. Rock who remarked that he also had been a member of the Track Committee, and consequently had nothing to criticize in the Paper, observed that on p. $505 \mathrm{Mr}$ Loach had given the factors which had been taken into consideration in selecting the maximum permissible cant, and referred to the case of a van having been overturned by a gale. $\mathrm{Mr}$ Rock had recently referred to a Paper ${ }^{1}$ presented to the Institution which dealt with the same subject and whose Author had deduced that it was unwise to specify a maximum cant of more than 4 inches, in view of the fact that an unloaded stationary covered van of a type common at that time, 27 feet long and of $9 \frac{1}{2}$ tons tare weight, could be overturned by a wind force of $20 \mathrm{lb}$. per square foot. That wind force, according to the only formula which Mr Rock had been able to find, was equivalent to a gale of 63.6 miles per hour. He had been sufficiently interested to see what the effect would have been if the track had been level, and had found that it would have required a wind velocity of 68.7 miles per hour, so that the difference between the speed of the gale required to blow the wagon over on level track and on track with 4 inches of cant seemed to be very slight. In fact, with a 6 -inch cant, which was recommended by the Track Committee as the maximum, the velocity to overturn the same vehicle would be 61.5 miles per hour. He submitted that the difference in those velocities was of little consequence compared with the advantage to be gained in permitting the extra 2 inches of cant, or, of course, of cant deficiency if the vehicle was moving round the curve and the wind was blowing towards the outside of the curve.

$\mathrm{He}$ commented on the remarkable agreement on the part of the thirteen "guinea-pigs" on each of the sensations recorded in turn. They had not all estimated the same sensation number, but the range on the whole, as Mr Loach would probably confirm, had been remarkably low. It was significant that although some of those who had taken part had a slightly more critical assessment of comfort than others, nevertheless the difference in sensation numbers on successive curves, as recorded by the various observers, was very consistent.

The fact that they considered on the average that a degree of discomfort began with 7 inches of cant deficiency had struck him on reflexion as being remarkable, in view of the fact that when going round an ordinary sharp curve on an uncanted road in a motor car, or going round a roundabout, at a speed of, say, 25 miles per hour, it was not unusual to attain a cant deficiency of 18 inches to 2 feet, and yet no particular discomfort was felt. It seemed to him that in a railway train people were influenced to

1 J. W. Spiller, "High Speed on Railway Curves." Min. Proc. Instn Civ. Engrs, vol. CLXXVI, pp. 83-84 (Jan. 1909). 
some extent in their assessment of comfort by what they had come to associate with travelling by train, as opposed to travelling in a car. Whether the height of the passenger above the surface on which the vehicle ran contributed to that difference he would not like to say, but it had struck him as being an interesting feature.

On pp. 534 and $535 \mathrm{Mr}$ Maycock described the selection of the virtual transition. Mr Brinsmead had mentioned the effect on passengers standing over the bogie at the end of a coach. The point should not be overlooked that the fortunate passenger in the centre of the coach travelled over a path which was that of the virtual transition, but the passenger over the bogie was subjected to an instantaneous application or relief of radial acceleration as the bogie passed over the tangent point. In switch-and-crossing work, even with a curved-blade switch where there was still a slight angle of divergence, a passenger either in the centre of the coach or over the bogie experienced an instantaneous change, but that was of little if any more significance than the other disturbances to which Mr Loach had very rightly drawn attention - the impact of wheel flanges against check rails, passing over crossing gaps and so on. For that reason Mr Rock supported the contention that it was wise to exercise a slightly tighter control over cant deficiency in switches and crossings, than in plain track on classes "A" and " B" lines.

Lieut.-Col. G. R. S. Wilson thought that the Paper and all that it dealt with represented true progress. Instead of the varying and perhaps unco-ordinated methods of the past a thorough study of the problem had been made, with the experience of all the former Companies behind it; and the results had now been codified in the rules and instructions which, he understood, were being issued by the Railway Executive. Not only had very careful mathematical theory been used, but also practical considerations had been taken into account, including the human factor. The agreement on sensations, as plotted on the graphs, seemed to be extraordinary, considering the different reactions of different people.

Colonel Wilson remembered the work which had been done on the problems presented by the high-speed trains which had been introduced in 1935 on the East Coast main route. He had travelled on one of the first test runs, and he remembered that right up to the outbreak of war, no doubt because of the attention and research given to the track, there had been a steady improvement in the running of those high-speed trains. The maximum speed permitted in actual service had been, he believed, 90 miles per hour, but he thought that they used to go quite a lot faster sometimes.

He remembered going round the Hatfield curves often enough in his journeys to the North. The speed used to rise to approximately 90 miles an hour with those light high-speed trains, and he would have described the sensation experienced as a certain feeling of insecurity, but he used to console himself with the thought that the outside wheels were thereby being pressed more firmly on the rail all the time. 
On looking through some of the Ministry's reports on main-line derailments, he had noticed that at Hatfield there was $2 \frac{3}{4}$ inches of cant on a 76-chain curve. On the other hand, at Polesworth on the L.M.S. Trent Valley line, on a 76-chain curve there was $4 \frac{1}{4}$ inches of cant. Both were high-speed routes. Presumably that represented the difference in practice which prevailed among the former Companies.

The question of maintenance was necessarily dealt with lightly in the Paper, by reference to "normal deterioration," "imperfections," and "discrepancies," but he would like to relate that to a point which Mr Brinsmead had made, or perhaps it would be more correct to say to a point which Mr Brinsmead had not made. Mr Brinsmead had said that one cause of derailment was overturning. It was well known that there had been few cases of overturning in the past ; Colonel Wilson could recollect only three, namely, those at Salisbury, Shrewsbury, and possibly Canal Junction, Carlisle, in 1930. Another cause which had been mentioned was the climbing of the flange over the high outer rail of the curve. In several cases which it had been the duty of Inspecting Officers to investigate, derailment had occurred to the inside of the curve. There was nothing extraordinary about that. There were the dynamic effects of rolling and lurching, together with the side-to-side movements of a long-wheelbase engine, and the consequent relief of weight on one of the wheels on the inside. That seemed to him to be very much related to cant deficiency, and he would also suggest that there was a relationship between cant deficiency and standard of maintenance.

A cant deficiency of $3 \frac{1}{2}$ inches for " $A$ " and " B" lines, and of $2 \frac{1}{2}$ inches for " $\mathrm{C}$ " and " $\mathrm{D}$ " lines, was the maximum permissible. The greater the cant deficiency, the more important was the maintenance of the regularity of the cant, because in any case, during steady running on a curve with a cant deficiency, it was axiomatic that there was some degree of relief of the designed weight on the inside locomotive wheels. That was inherent, and if it were increased by lurching and rolling, and by dynamic effects and irregularity of cant, the higher the designed deficiency at any given speed the greater was the proportional relief of weight on the inside of the curve.

Track maintenance was not susceptible to the same standards of accuracy as mechanical engineering, since natural materials were involved. As a supplement or sequel to the present Paper, might it not be very useful to draw up something in the way of tolerable standards, by classes of line and types of curve, for irregularity or permissible variation from perfection? He suggested that such standards would no doubt be very difficult to get down to because they were not so susceptible to scientific treatment as present design standards, but how far was it possible to go with safety ? What could a permanent way inspector tolerate? What could a ganger tolerate? What could be tolerated before it was necessary to restrict the speed?

He had been looking up what the maximum cant gradients in a few 
cases of derailment had been, and what was the actual worst cant gradient found. (He was not now referring to the Weedon accident, with which he had been concerned recently, because that had not been a track case at all but had had an entirely different cause.) He had found that the cant gradients ranged from 1 in 300 at the worst to 1 in 1,080. There were, however, reversals of cant in some cases, high-low-high-low in wave form, which had set up rolling and lurching and had led to derailment to the inside of the curve. He hoped that consideration would be given to a sequel to the present very valuable Paper on the lines he had suggested.

Mr A. I. Emerson commented on the practical application of the code of practice which the Authors had suggested. His remarks were based upon experience with a similar code of practice which had been introduced on the L.N.E.R. a few years prior to nationalization.

From the point of view of the designer the code of practice given in the Paper was very helpful, because it almost reduced the determination of maximum permissible speeds on curves to a simple arithmetical calculation admitting of one solution only, and even that work had been almost eliminated by means of the graphs which Mr Maycock had shown. Mr Emerson said "almost" because the code did not directly indicate the amount of cant which should be used in the calculation; the designer was left with the task of assessing the actual amount of the cant after giving consideration to the particulars which were set out on p. 530, namely the speed limit, the speed restrictions, the gradients, and the nature of the traffic. It was therefore essential that those factors should be fully considered, and, as Mr Maycock had pointed out on p. 540, that was best done by making a review of conditions on the route, as opposed to individual consideration being given to each curve.

Mr Emerson stated that a speed-distance chart was an essential preliminary to making any such review and showed a slide of a chart having three speed lines for each track :

1. The speed limit and speed restriction line;

2. The speed of an ordinary express train (obtained during a Hallade record run);

3. The record for a high-speed train (representing the maximum requirements of the Operating Department in the near future).

The other information given on that simple form of speed/distance chart had been limited to the magnitude and direction of curvature, gradients, and mileages. The designer might, however, require a chart to a larger scale, so that further details of curvature could be added, together with a line diagram of the permanent way layout. If it were to be used by those responsible for the timing of trains, dimensions would be added relating the speed limit and speed restriction line to the timing points, such as signal boxes.

The code of practice could be applied to curves whether they had been 
re-aligned or not. In the latter case the designer had to carry out additional work before the factors governing cant could be properly assessed and the code of practice applied. Mr Loach had distinguished between curves which had been re-aligned by the Hallade method and those which had not.

On routes which had been re-aligned, a suitable speed/distance diagram might already be available; but, owing to the work having been spread over some time and carried out by different individuals, it was possible that uniform treatment might not have been given to the very important governing cant. Overall consideration of those factors for the route, and especially of the estimated speed limit, would enable the code of practice to be applied to determine the maximum permissible speed on each curve on a consistent basis.

On routes which had not been re-aligned, a reliable speed/distance chart would not be available, and before the code of practice could be applied the designer had to carry out additional work on the ground in taking particulars of the curves. He had then to regularize the existing versines and cants which he had obtained and to use his judgement in distinguishing between irregularities due to faulty maintenance and those which could be put right only by major or minor re-alignment schemes. The extent to which re-alignment was required to avoid an excessive number of speed restrictions could be decided only after considering the route as a whole; again, if a speed/distance chart were prepared, the work was greatly facilitated, and the code of practice could be properly applied even to curves which had not been previously re-aligned.

Engineers responsible for fixing maximum permissible speeds would be very interested in the tests which the Track Committee had carried out in order to assist them in determining the limiting values for deficiency of cant, and for the ratio of change of cant and of deficiency and so forth. Mr Emerson showed some slides illustrating actual running at higher speeds (about 60 miles per hour) than those for which the Track Committee had recorded their sensations (40-45 miles per hour). The curves were 32-chain reverse curves on an important main line carrying express trains.

One slide showed the versines and the cants which had actually been applied to the track in accordance with the code of practice formerly used by the L.N.E.R. The maximum permissible speed according to that code of practice was 60 miles per hour, and the limiting factors were the rate of change of cant deficiency and the rate of change of cant, both of which were at their limiting value of $1 \frac{1}{2}$ inch per second. The slide also showed the cant which would be applied according to the code of practice suggested by the Authors. The maximum permissible speed had been increased to 65 miles per hour, and the limiting factor was the deficiency of cant on the circular part of the curve, which was then 2 inches. The rate of change of cant was slightly below its limiting value at 65 miles per hour; it was only $2 \frac{1}{8}$ inches instead of $2 \frac{1}{4}$ inches per second. The versine-cant diagram displayed by Mr Emerson illustrated the differences between the Authors' 
code and the former L.N.E.R. code, which had been rather more conservative.

Mr Emerson showed a reproduction of an actual Hallade record at an average speed of about 68 miles per hour on the same curves. The deficiency was $\frac{3}{4}$ inch (or 40 per cent) more than that recommended by the Authors, and on the transition the rate of change of cant was 21 inches per second, which was the Authors' limiting value. In spite of that and of the high speed, the Hallade record showed the riding to be reasonably good both on the circular part of the curve and on the transition. However, a regular traveller travelling at 68 miles per hour would probably experience sensations of a somewhat different nature from those felt by the Track Committee during their tests, which had been made at a rather lower speed. Sensations were difficult to describe, but it might perhaps be said that the traveller would " anticipate" discomfort. When crossing work had been reached further round the curve rather bad riding had occurred, and was probably due to the lateral forces caused by the check rails.

Mr Emerson appreciated that that one example did not do much to support the conclusions arrived at by the Authors for fixing the limiting values for cant deficiency and so on, but he thought that many more cases could be shown which would help to justify the code of practice which they had suggested. It would perhaps be interesting to see whether on flatter curves with a lower cant a higher deficiency could be permitted, because, as Mr Taylor Thompson had said, before the war, high-speed trains had been running on flat curves (which had been, of course, very well maintained) at much higher deficiences and at speeds of over 100 miles per hour.

Mr W. E. Gelson observed that the provision of sufficient cant to meet the requirements of comfort was not always enough to ensure a satisfactory safety margin at high speeds, particularly when the driver had somewhat under-estimated the speed. That had been appreciated by $\mathrm{Mr}$ Loach, as was shown by the remarks on pp. 514 and 515. That aspect required reference to experiments on the riding of locomotives, a large number of which had been made during the past 20 years in various countries. Those experiments had shown that a given value of cant deficiency at speeds below 45 miles per hour, on broad and standard gauge, had a far less disturbing effect on the track than it had at the higher speeds. It would therefore appear that the amount of cant deficiency provided should be closely related to normal maximum speed.

There had in the past been more derailments on curves due to lateral thrust than to overturning under the action of centrifugal force. On p. 531 Mr Maycock had stated that it was not always necessary or desirable to use the maximum allowable cant deficiency, in order to facilitate track maintenance. That was extremely sound policy. There were doubtless not a few main line curves where greater speeds would be practicable if a cant greater than 6 inches could be provided. In cases where the speed of the slowest train was sufficiently high, Mr Gelson suggested that some increase 
above 6 inches could be given, provided tapered sleepers were used, possibly in conjunction with a special sub-frame, in order to ensure stability of the under-ballast.

Mr K.H. Tredinnick said that on p. $537 \mathrm{Mr}$ Maycock had referred to the speed of trains through turnouts, and on p. 536 had given a formula for relating the speed at the tangent point of a curve where there was no transition. Mr Maycock had made some mention of his reason for the higher speeds allowed through turnouts, but Mr Tredinnick was not clear about that and would like some amplification. He thought that if the speed round a curve was restricted on account of lack of transition in plain line, there should be a greater restriction provided through a turnout, where there were more difficulties, particularly in divergence of switch.

Mr Loach had referred on p. 519 of the Paper to the $P / W$ ratio. Mr Tredinnick was not clear whether the minimum cant gradient of 1 in 300 which was referred to had been arrived at as a result of considering the twisting force due to the actual cant run-out on which $\mathrm{Mr}$ Loach superimposed a 1 in 300 theoretical cant deficiency run-out. It was thought that the $P / W$ ratio due to the twist of the actual cant run-out would increase considerably when coupled with an unequal wheel loading due to cant deficiency.

Mr Rock, Mr Loach, and Mr Taylor Thompson had said that there was very little harm in cant deficiency, and that the experience of a person travelling in a train would be one of no discomfort even up to a figure of possibly 4 inches on a fairly badly-aligned curve. If that were the ease, and if the recommendation of $3 \frac{1}{2}$ inches mentioned by Mr Loach were based only on stress considerations, particularly on fastenings, $\mathrm{Mr}$ Tredinnick would disagree with the Table and with the recommendations made by the Authors that cant deficiency should vary with actual cant, which was referred to in Table 5, p. 527. He thought that in considering cant deficiency it was useful to get back to first principles on the subject.

Cant deficiency was no more than a convenient name, in the absence of a better one, for an unbalanced centrifugal force which came into effect when travelling at a speed greater than the equilibrium speed. On any curve it was also possible to get an inwards force due to cant surplus; in other words, an inwards force due to a slow-moving train. He thought that in the interests of track economy, and particularly in respect of fair wear and tear of track, it would be better to balance the outwards force due to the speed above the equilibrium speed with that of the inwards force due to the difference between the equilibrium speed and the speed of the slower train. The condition to allow those two forces of eant deficiency and eant surplus to be equal would be

$$
V_{m}^{2}-V_{e}^{2}=V_{e}^{2}-V_{s}^{2}
$$

where $V_{s}$ denoted the speed of the slower train, $V_{m}$ the maximum speed in accordance with Mr Emerson's timing-of-trains diagram, and $V_{e}$ the equilibrium speed. That could be developed further to give the following formulae : 


$$
E \text { (actual cant) }=\frac{0.03}{R}\left(V_{m^{2}}+V_{s}^{2}\right)
$$

and

$$
D \text { (deficiency of cant) }=\frac{0 \cdot 03}{R}\left(V_{m}^{2}-V_{s}^{2}\right) \text {. }
$$

Those were reasonably simple formulae and gave excellent practical results. Speed restrictions could be defined by the maximum of $E=6$ inches or $D=3 \frac{1}{2}$ inches, whichever was reached first.

The Authors had dealt at great length with various theoretical considerations in arriving at a $3 \frac{1}{2}$ inches cant deficiency and so on, and stated that they had also experienced all sorts of sensations on the Bettws-yCoed line ; then on p. 526 of the Paper they suddenly adopted an empirical formula which appeared to be without proof, and which made cant deficiency a function of actual cant. So far as Mr Tredinnick was able to interpret their Paper, their excuse for that was that maintenance problems demanded a varying cant deficiency, and they inferred that those maintenance considerations applied only to the fastest trains. On p. $531 \mathrm{Mr} \mathrm{May}$ cock had, in point of fact, stated that on lines where freight traffic was considerable a maximum speed restriction could be imposed on the faster trains. That in itself appeared to be a confession that the effects on track from the point of view of maintenance were as much attributable to the slow-moving traffic as to the fastest traffic. Mr Tredinnick was of opinion that a slow-moving train on a heavily canted road probably had more illeffects than a fast train, as it bumped and bored its way along contributing to gauge-widening and many other evils, all of which defects reacted on the comfortable running of the fast trains. In his opinion, therefore, it would have been better either to have adopted a formula such as he had indicated, which catered to some degree for the ill-effects of both the slow and the fast train, and was economical from a rail wear and maintenance point of view, or to have confined the recommendations to those contained in Table 4, and to have left the rest to the engineers on the site, who knew all about local site conditions and the ranges of traffic to be dealt with, and who could be trusted to get the maximum out of the job from the point of view of track strength, track life, speed, and good time-keeping.

Table 5 allowed for reduced deficiency at the higher actual cants, and as such would not fully cater for the slower train, but tended to have the effect of causing increased maintenance problems and track wear, in addition to being a restrictive practice which would tend to reduce speeds.

With regard to the " $C$ " and " $D$ " lines, those were covered in any case by an overall speed restriction, and it was usual to find on that class of line a greater proportion of slow-moving traffic. He thought that the fact that the Authors had further restricted permissible cant deficiency at the higher ranges of cant in that case would worsen the situation and increase wear and maintenance problems due to slow trains. He considered that it was a pity that a stop had not been made at the recommendations 
in Table 4, leaving all questions going beyond that to the engineers responsible for the work, who could choose the actual cant and cant deficiency within the maximum limits laid down to suit local conditions.

*** Mr G. D. S. Alley remarked that Mr Loach would be interested to know that comfort was considered by the L. \& N.W. Railway when deciding on the allowable deficiency of cant. It had been found that to travel at 20 miles per hour round a curve of 10 chains radius without any superelevation did not produce any undue feeling of discomfort, and was perfectly safe. The figure of $2 \frac{3}{8}$ inches was therefore used as a maximum allowable deficiency of cant on that Railway, and for some years after the formation of the L.M.S. on quite a large area of the latter.

With regard to Mr Loach's comments on the difficulty of maintaining track with more than 4 or $4 \frac{1}{2}$ inches of cant, Mr Alley differed and stated that surely that depended solely on the traffic and the speed of such traffic on the track in question. For example, with a 50-chain-radius curve and practically all the traffic passing at speeds between 65 and 75 miles per hour, there should be less difficulty in maintaining good top and line with 6 inches of cant than there would be in maintaining straight trackformation, ballast conditions, etc., being comparable. On the other hand, should there be a large amount of traffic at speeds of 40 to 50 miles per hour with only one or two trains at speeds of 80 to 70 miles per hour, it would be difficult to maintain a cant of 6 inches, and such a cant should not be used in that case.

Mr Alley noted from Fig. 16 that three half-chord points were shown on the transition together with the half-chord points at each end. On Fig 17, however, only two half-chord points on the transition were shown, and it was considered that the necessity of a minimum of five half-chord points per transition, including those at each end, should be stressed to ensure accurate setting-out and ease of maintenance.

A minimum length of transition was again quoted on p. 535, whilst a desirable transition of only 89 feet was shown on Fig. 17. That, presumably, was to justify a cant deficiency, but surely each case required consideration on its merits within the limits laid down. If on a compound curve it was considered good practice to provide the cant for equilibrium speed on one part, why suggest to a designer that he should provide less than that required for equilibrium speed elsewhere on the same curve, unless the site conditions were such as to make that necessary or the cant required for such speed was more than the limit of 6 inches laid down previously?

Mr D. H. Coombs observed that there had apparently for some time been fair agreement in Europe that the maximum value of cant, expressed as a tangent in the form $\frac{\text { cant }}{\text { gauge }}$, should be between 0.08 (German railways)

${ }_{*}^{*}$ * This and the following contributions were submitted in writing. $\rightarrow$ Snc. I.C.E. 
and 0.1066 (French railways), with exceptionally the P.L.M. system using 0.131. Most European railways appeared to favour a maximum cant equivalent to $\frac{1}{10}$ gauge, where gauge was the gauge between rail axes.

On 4-foot-8 $\frac{1}{2}$-inch $+2 \frac{3}{4}$-inch gauge, 6 inches was equivalent to $\tan ^{-1}$ $0 \cdot 101$. The decision for 6 -inches maximum cant could therefore reasonably be regarded as in line with general European practice.

There seemed to be a fair measure of opinion on the Continent that $3 \frac{1}{2}$ inches of cant deficiency, or about 1.9 feet per second per second unbalanced centripetal acceleration, was reasonable, but that deficiencies greatly in excess of that might be dangerous, though the Italian railways used up to $3 \cdot 285$ feet per second per second, or about 6 inches of cant deficiency. From the passenger tolerance point of view the experiments appeared to show that 4 feet per second per second (which was equivalent to $7 \frac{1}{4}$ inches cant deficiency) was a reasonable imposition as such, but that owing to line imperfections it was wiser to limit it to rather less than half of that value. The decision for $3 \frac{1}{2}$ inches of maximum cant deficiency could therefore be described as orthodox.

Referring to Figs 2, Plate 1, the portion of the 40-miles-per-hour Askania trace relating to the entry transition of Curve No. 5 showed a maximum unbalanced radial acceleration of about $3 \frac{1}{2}$ feet per second per second. But considering the first differential of that trace, that was, the rate of increase of unbalanced radial acceleration, it appeared that in the transition to curve No. 5 a rate of increase of about 6 feet per second per second in a second (equivalent to about 11 inches gain of cant deficiency in a second) was registered during the actual achievement of about $3 \frac{1}{2}$ feet per second per second. Here it would clearly be the $P t=m f t$ aspect which would give discomfort rather than the $P=m f$ evaluation. Furthermore, since the total journey-time through that transition was about 2 seconds, it would, Mr Coombs thought, be quite impossible for the observers to distinguish the impulsive aspect from the growth of cant deficiency as such. The same sort of complication masked subjective evaluation of the constant unbalanced radial acceleration over circular curve No. 5, and to a somewhat lesser extent on circular curves Nos 3 and 4.

It followed that before cant deficiency itself could be measured subjectively, a very long curve in a very high state of curve regularity was necessary, otherwise the observers could not hope to distinguish between the effects of cant deficiency and those of line deficiency.

From what had been said previously it would appear that the possibility of subjectively measuring a quantity compounded of tilting, a gradual increase of cant deficiency, and irregularities of line, was not very great unless the transition was long and regular, with an easy cant gradient. The failure of correlation of the sensation numbers with measured cant deficiencies in the second range of transition curves was not surprising. The wonder was that the array of sensation numbers relating to curves Nos 1 to 14 was as statistically as significant as it was; though if the gains 
and losses had not been averaged, as he assumed they had been, the scatter would have been more random even with the Nos 1 to 14 series.

The maximum rate of loss or gain of $2 \frac{1}{4}$ inches per second adopted. therefore appeared to be slightly conservative in the light of the relevant observations, but was probably an adequate ceiling for most track designers.

The publication of the random scatters obtained on curves Nos 15-52 was, he thought, to be appreciated as a gesture of scientific honesty.

He remembered having, in the past, put cant on to a sharp curve at what he had then thought to be the maximum safe rate of $1 \frac{1}{4}$ inch in 33 feet, or 1 inch in 26.5 feet. From his knowledge of the train speeds, as electrically recorded, he had known that the higher speed was 34 miles per hour, thus involving a gain of cant of nearly 2 inches per second. At that time he had regarded that as somewhat daring, because Mr Taylor Thompson, in his Paper ${ }^{1}$ published in 1938, had suggested that whilst American Railroads adopted 1.22 to 1.5 inches per second, his own experiments had shown that 1.7 inches was quite comfortable; though he counselled that only that 1.5 inch could be adopted with safety. However, travelling over the 1 in 320 gradient at 34 miles per hour Mr Coombs had found that he could just feel the approximately 2-inches-per-second roll and that, he thought, was because he was conscious of its location. It was a piece of track that he had subsequently travelled over frequently, but without thinking about it at the right moment he never noticed it.

He was in doubt as to the expediency of using so steep a cant gradient as 1 in 300 at one sort of location, a sharp reverse curve without any intervening straight, not with regard to wagons but with regard to locomotives with more than two coupled wheels, and with travelling cranes with two or more fixed axles. With those vehicles there might be a danger that the rigid wheelbase and very stiff springing, in combination with conterminous 1 in 300 gradients, and defects in track maintenance, might cause a shifting of weight, not from the inner wheels to the outer wheels, but from the inner axles to the outer axles when, if for one reason or another, the springs could not easily follow the contour of the rails; then there was a possibility of derailment following an acceleration or deceleration surge in the engine or train.

That position could be made worse by the presence of a vertical curve which was concave upwards across the transitions. It followed that the definition of a radius minimum for vertical curves was a desirable complement to the definition of a maximum cant gradient.

Mr A. W. T. Daniel observed that the proposed new limits for cant, cant gradient, and rate of gain of cant appeared to be logically developed from basic considerations and experimental observation, and were a great advance on the old-fashioned rule-of-thumb methods ; but certain questions

1 "Railway Track Work for High Speeds." Paper read before Yorks Assoen Instn Civ. Engrs, March 1938. Abs. printed in J. Instn Civ. Engrs, vol. 10, p. 405 (Dec. 1938). (The full MS. and illustrations may be seen in the Institution Library.) 
arose regarding cant deficiency. On p. 526 of the Paper formulae were given connecting $D$, the cant deficiency, with $E$, the actual cant, which had the effect of giving $D$ decreasing values for increasing values of $E$; the reason advanced for that, on p. 516, was the greater influence of track imperfections at the high speeds associated with the higher cants. But since it would seem more likely that the highest speeds would be developed on straights or slightly curved track, where the cant would be either zero or small, an equally valid case could be made out for increasing $D$ as $E$ increased, instead of the reverse.

A more logical solution would apparently be to decide on a constant value of $D$ for all values of $E$ on plain curves; or else to adopt a method as suggested by Mr Tredinnick, which led to the equations :

$$
e=\frac{s}{2 g r}\left(v_{m}^{2}+v_{s}^{2}\right) \text { and } d=\frac{s}{2 g r}\left(v_{m}^{2}-v_{s}^{2}\right)
$$

where $v_{m}$ and $v_{b}$ denoted the greatest and least speeds at which trains were expected to traverse the curve, all in foot-second units. Actually, since a train might be stopped on a curve, in the limit $v_{s}=0$ whence $d=e$, which showed the impossibility of allowing for all conditions, and it would probably be simpler, and equally logical, to adopt a constant value of $D$ for plain curves as he has just suggested.

Turnouts presented a special problem, since at the switch points there was a sudden change of direction, usually associated with zero cant. According to pp. 526 and 537 of the Paper that was to be dealt with by using the formula as for classes " $\mathrm{C}$ " and " $\mathrm{D}$ " lines, and taking $R$ as the radius of the turnout curve. But the governing factor was the sideways impulse set up at the switch points, which depended on the mass and velocity of the vehicle and the angle of the switch rail, and was independent of the subsequent switch and turnout radii. That could not be dealt with by canting the track in the usual manner, and to assume a radius equal to that of the turnout, even when it was less than the switch radius, was at best a sweeping approximation. A more logical procedure would appear to be to lay down maximum speeds for each type of switch rail, which would have to be determined by experiments conducted from the point of view of passenger comfort.

The high degree of uncertainty governing the speeds at which turnouts could be entered was illustrated by the manner in which negative cant was dealt with. Taking the example on p. 537, if $E=-1$ inch, then $D$ should be $2 \frac{3}{4}$ inches according to the formula, but the value given of $2 \frac{1}{4}$ inches could be obtained only by ignoring the sign of $E$ and using the formula as if it were positive. The reasons for that procedure were not quite clear, and again it would appear to be equally logical to adopt constant values of $D$ as he had suggested.

A matter which did not seem to be mentioned in the Paper was that of compensating curves. To suggest an example, considering a line having a 
ruling gradient of 1 in 200 , if a curve had to be laid to that gradient and the limiting value of 1 in 300 for cant gradient were applied to the outer rail, then that rail would have an actual gradient of 1 in 120, and the centre of gravity of the train would have to be lifted through the average gradient of 1 in 150. The Authors of the Paper had stated that each individual case should be considered on its merits, but it would be of interest to know if it was intended in the future to draw up a set of rules governing problems such as that just considered.

Mr Loach, in reply, expressed his thanks for the kind reception given to the Paper, and thanked all those who had made constructive comments and criticisms.

Several speakers had referred to the question of the different sensations, and to the possibility that the thirteen observers who had submitted themselves to the tests had recorded different sensation numbers. They had done so to a slight extent, but on the whole the agreement had been good. Two members had consistently recorded higher than the average, and two consistently lower, but eight or nine of the thirteen had usually recorded within 20 per cent of the average figure, taking the totals for each test. Fven though there had been little difference in the sensations described by two consecutive numbers, some of the observers had used half-numbers on occasions. It might be of interest to mention that No. 6 had not often been used, except by one member; even on the high-speed run most of the observers had recorded 4's and 5's, and so six numbers appeared to cover the required range of sensations quite satisfactorily.

Lieut.-Col. Wilson had spoken about flange-climbing derailments. It was true that most derailments occurred as a result of flanges climbing rails rather than from vehicles overturning, but Mr Loach thought the flange would only climb up the inside rail of the curve if the riding were very unsteady. Normally, the deficiency of cant would help to force the leading flange of the vehicle even harder against the outside rail than would be the case if the vehicle were running at equilibrium speed. At the same time, of course, more vertical weight was carried by the outer rail, that weight having been taken off the inner rail.

The suggestion that permissible limits of irregularity should be determined was very interesting. Most of the limitations mentioned in the Paper had been imposed as the result of sensations, so that the question of safety would arise only with considerably greater rates of gain or loss of cant and of cant deficiency than those which had been suggested in the Paper as limiting values to be used in design. The question of cant gradient was a different one, and in that respect he was about to embark on some work on vehicles other than four-wheeled wagons to find out more about it. He hoped that he would still find there was an adequate margin of safety on a 1-in-300 gradient, and to establish that he was proposing to make tests on artificial cant gradients steeper than 1 in 300 .

Mr Tredinnick had raised the question of the $P / W$ ratio for long four- 
wheeled vehicles. The vehicles had been weighed, when placed on artificial cant gradients on a weighbridge, to find the redistribution of weights when unladen, and hence the $P / W$ figures had been calculated. Admittedly, if there was very unequal loading, such as a diagonally placed load which radically redistributed the weights, the situation might be worse than the figures had suggested, but a load should not be permitted to run unless it was within reasonable limits of symmetry, and then it would not, $\mathrm{Mr}$ Loach suggested, alter the distribution of weights to such an extent as to make the position worse than when the vehicle was unladen.

$\mathrm{Mr}$ Tredinnick also seemed to disagree with the idea of grading down the cant deficiencies. Mr Loach suggested that it was largely a question of maintenance. He had mentioned in the Paper what the Track Committee felt about the question of maintaining track which was steeply canted; it was usually more difficult than with track which was not so steeply canted. If there were large cant deficiencies in addition, it was going to be a real problem. The whole situation had to be considered in the light of what could be done with a reasonable amount of man-power and without having to give undue attention to any particular portion of the line.

Mr Alley's description of how the maximum permissible cant deficiency had been settled on the former L. \& N.W. Railway was interesting, but, apparently, very incomplete. Mr Loach suggested that if that figure had been settled so long ago, the Track Committee were fully justified in making trials with modern recording instruments. The result had given an increase of more than 50 per cent in the permitted maximum deficiency, and the increase was a boon at places where no cant could be allowed.

Mr Loach agreed with Mr Alley that a curve with 6 inches of cant would be no more difficult to maintain than any other if all trains were to run round it at equilibrium speed, but, for a specified speed, the more highly canted curves were of smaller radius and any deviation from the equilibrium speed gave a greater deficiency or excess of cant than would be the case on a large-radius curve when the same deviation from equilibrium speed occurred. Mr Loach suggested that, in practice, there were relatively few curves with 6 inches of cant over which all trains ran at speeds within 7 per cent of the equilibrium speed. (That 7 per cent was based upon Mr Alley's figure of 65 to 75 miles per hour for a curve for which the equilibrium speed was 70 miles per hour.)

Mr Coombs has referred to the Askania accelerometer records; those had, of course, included the rolling of the coach, which accounted for many of the small irregularities in the traces obtained. To cause such "waves" in the trace little rolling of the coach was necessary-so little, in fact, that it would be barely perceptible to the passenger. For assessing the results they had been ignored, measurements having been obtained from the best straight line drawn through each portion of the trace. Mr Loach considered that that course was quite justified because a passenger did not experience the same discomfort owing to rolling (which caused variations 
from a mean line of the order of those under discussion) as that which he experienced owing to unbalanced centrifugal force. In much the same way a passenger barely sensed 2 inches excess of cant on a left-hand curve but he would be quite aware of 2 inches deficiency of cant on a right-hand curve, although both conditions would give exactly the same record on an instrument.

Mr Coombs had doubted the advisability of using a 1-in-300 cant gradient at reverse curves without any intervening straight, but Mr Loach considered that so far as twist of the track was concerned the conditions at the point of reverse were the same as elsewhere on the cant gradients. Vertical curves and defects in track maintenance were undesirable anywhere on steep cant gradients but no more so at the point of reverse than elsewhere. In fact, at speeds other than the equilibrium speed, the weight distribution at the point of reverse would be more nearly correct than elsewhere and the flanges would not be bearing hard against either rail. It should also be borne in mind that short lengths of straight between curves of opposite flexure often caused vehicles to roll more than if the curves joined.

Mr Maycock, who also replied, noted that Mr Orchard had expressed doubt about the need for two different ranges of cant deficiency, one for Class " $A$ " and " $B$ " lines and another for Class " $C$ " and " $D$ " lines, and had pointed out that the margin between the speeds allowed by the two rules was very small. Mr Maycock admitted that the difference of speed was not great, but considered that it was worth making a distinction in speed between the two groups of lines because of the slightly weaker track material used in " $\mathrm{C}$ " and " $\mathrm{D}$ " lines and the generally lower standard of maintenance.

Mr Orchard had suggested that the maximum cant gradient should be $\mathbf{1}$ in $\mathbf{3 6 0}$ so as to be a multiple of the rail length, but Mr Maycock said he would prefer that the lower figure of 1 in 300 should be retained. It should be remembered that that gradient was laid down as a maximum and that easier gradients would generally be used. He saw no great advantage in relating the gradient to the rail length, especially as rail lengths were not invariably uniform. The figure of 1 in 300 had been introduced as a result of tests made on the derailing tendency of long-wheel-based four-wheeled wagons, as explained by Mr Loach. Mr Maycock hoped that action would be taken to eliminate the worst of those wagons and that future designs of long four-wheeled wagons would be modified so as to reduce their tendency to derail on steep cant gradients.

Lieut.-Col. Wilson had mentioned the wide difference of cant on two curves of the same radius, both being on high-speed lines. Mr Maycock considered that the application of the rules given in the Paper would tend to reduce such differences of practice, but, as he had pointed out, it was impossible to give a precise rule for the amount of cant to be provided. It was necessary to decide on the speed for which equilibrium cant was to 
be provided, and that was a matter for judgement, taking into consideration the circumstances in each case.

Mr Maycock attached importance to route-speed diagrams of the type shown by Mr Emerson. They gave a clear picture of the speed conditions over the whole route and were of great assistance when a series of curve adjustments were being dealt with. Since they showed actual recorded speeds, as well as maximum permissible speeds, they were sometimes useful in proving that higher speed limits were unnecessary, in order to shorten train timings, if full advantage were to be taken of the present maximum permitted speeds.

The curve realignment diagrams shown by Mr Emerson were based on principles used on the former L.\&N.E. Railway, which were very similar to those presented in the Paper. The Hallade records taken on those curves showed that the application of those principles would give comfortable running.

Mr Maycock expressed interest in the formulae quoted by Mr Tredinnick and would like to study their effect.

In reply to Mr Alley's comments, Mr Maycock observed that the actual number of half-chord points shown in Figs 16 to 18 had no precise signifcance; the number would vary according to the length of chord chosen and the length of the transition. He did not consider it necessary to adhere to a minimum of five such points where short transitions were used. The example illustrated in Fig. 17 (p.533) was intended to show how suitable values of cant, deficiency of cant, and length of transition might be obtained from the graphs, and how the cant and the deficiency of cant should change from one part of the curve to the other. Clearly, each case had to be considered on its merits and a suitable selection of values made. He did not consider it necessary in all cases to provide equilibrium cant on each part of a compound curve, nor was it always desirable to do so. If that had been done in the case illustrated a longer transition would have been required.

In regard to Mr Daniel's criticism of the graded cant deficiency, Mr Maycock pointed out that the greatest need for a high cant deficiency arose on curves where no cant, or very limited cant, could be provided. That fact, together with the maintenance considerations mentioned by $\mathrm{Mr}$ Loach, justified, in the Author's view, the graded-down maximum cant deficiency as compared with the uniform deficiency suggested by $\mathrm{Mr}$ Daniel.

The formulae quoted by Mr Daniel were another form of those suggested by Mr Tredinnick. By their use, cant was selected to suit an intermediate speed in such a way that the outward force due to cant deficiency at the highest speed equalled the inward force due to surplus cant at the lowest speed. Presumably it was claimed that by thus equalizing those opposite forces wear and tear of the track was reduced to the minimum. That might be so in particular cases, but since the formula :

$$
V_{m}^{2}-V_{e}^{2}=V_{e}^{2}-V_{s}^{2}
$$


took no account of the weight or number of trains travelling at the two extreme speeds, $\nabla_{m}$ and $V_{s}$, or at any intermediate speeds, it was by no means certain that the total outward forces would balance the total inward forces, and result in the minimum wear and tear of the track. On p. 530 Mr Maycock had pointed out the weakness of such formulae and took the view that the speed for which equilibrium cant should be provided should be selected by careful judgement of the circumstances of each particular case.

Mr Daniel had suggested that the maximum speed for each type of switch should be determined by experiment. The severity of the divergence at the switch was, however, affected by the curvature of the main line through the turnout, and a large number of tests would be required to cover every possible variation of the angle of divergence for each type of switch. The thrust at the switch was instantaneous and was so quickly followed by that on the turnout curve that it would probably be difficult to distinguish between the two sensations of discomfort. It was unlikely that a simple rule could be formulated as a result of the tests. The Track Committee had approached the problem with a view to devising the simplest possible rule. The curvature of the branch or turnout curve in standard leads from a straight main line bore a definite relation to the angle of divergence at the switch. Both were affected if the main line through the turnout was curved, but a relation still existed between the two. It was considered that the radius of the turnout curve gave the most convenient measure of the severity of the divergence at the switch in all circumstances, whether the main line was straight or curved, and it had therefore been decided (as explained on p. 537) to base the maximum speed for the whole turnout, including the switch, on the radius of the turnout curve, and at the same time to make some allowance for the sudden thrust at the switch by using a lower maximum deficiency of cant. The simple practical rule thus obtained gave maximum speeds which experience had shown to be within the limits of comfortable running.

With regard to Mr Daniel's comments on turnouts with negative cant, the value to be taken for $D$ (as stated on p. 537) was the same for negative as for positive cant ; thus in the example given, where the negative cant was 1 inch, $D$ would be $2 \frac{1}{4}$ inches. That procedure gave the desired effect of reducing the maximum permissible speed as the negative cant increased.

\section{Correspondence}

Mr T. D. Turner observed that his particular interest in the Paper lay in the application of the Authors' recommendations to the design of curves for high-speed traffic and their effect on switch-and-crossing work.

It would be appreciated that for comfortable high-speed running and 
ease of maintenance, the curvature and cant through a curve should be as regular as possible so as to avoid changes in cant deficiency and excess at speeds other than the equilibrium speed.

For junction work, it was often necessary to flatten the curvature in order to reduce the cant requirement at switches and obtuse crossings and, in addition, to run at a cant deficiency on the main line through the junction. Such compounding of the curvatures could be effectively transitioned, and a reasonable cant and cant-deficiency gradient could usually be obtained, particularly if the main line carried a speed restriction through the junction.

In the case of trailing crossovers and trailing connexions to sidings, etc., it was not normal practice to compound the main-line curve or reduce the main-line cant in order to restrict the negative cant over the connexion. The application of main-line cants greater than $2 \frac{1}{2}$ inches through such connexions had been appreciated by $\mathrm{Mr}$ Maycock in the paragraph headed "Turnouts with Negative Cant," but the restriction of the negative cant to 3 inches in the switches would involve many additional main-line speed restrictions.

On such connexions, too, it was normal practice to reduce the negative cant progressively between the switches and the crossing by adzing, packing, or, in recent years, by the use of thick-base chairs. Cant gradients as high as 1 in 200 had been applied in those cases without detriment and with a considerable easement in the maintenance. Tests carried out some years ago upon the then L.M. \& S.R. system, using rigid-frame locomotives, had proved that a 1-in-200 cant gradient could be safely accepted at low speeds ; Mr Turner would be interested to have the Authors' opinion on the application of such a cant gradient in the type of connexion to which he referred.

In trailing crossover roads between curved main lines, the cant gradient that could be "built-in" the connexion by means of two-level switches and thick-base chairs determined the relative levels of the running lines with the applied main-line cant. A cant gradient in the crossover of 1 in 200 was often necessary where the connexions were in close proximity to station platforms or tight overhead structures, and where a reduction in the mainline cant would involve a severe speed restriction on a high-speed curve.

Mr Maycock's principle of using the distance between bogie centres as a virtual transition had an interesting application when the versine on a chord equal to the bogie centres was measured at the toe of standard switches. It would be found that the versine at the toe of " $\mathrm{D}$ " switches, referred to as an example on p. 537, gave a resultant cant requirement of more than 3 inches at that point, the centre of the virtual transition, which compared unfavourably with the cant requirement of $2 \frac{1}{2}$ inches through the turnout radius of 21 chains, at the quoted speed of 29.5 miles per hour.

The substitution of " $E$ " switches into the " D" heel chairs reduced 
the effective cant requirement at the toe of the switch to $2 \frac{1}{2}$ inches, thus enabling a constant cant deficiency to be attained throughout the turnout.

To carry the process a stage further, " $E$ " switches fitted into " $D$ " heel chairs with a 1-in-10 crossing gave a turnout lead closely approximating a transition, and by the use of a two-level switch and thick-base chairs in the turnout curve, a constant cant deficiency of $2 \frac{1}{2}$ inches could be attained throughout that transitional lead.

That procedure had been extended on the L.M.S.R. system to cover "long $\mathrm{C}$ " and "long $\mathrm{E}$ " switches, with a consequent speeding-up of traffic over main-line junctions and a saving in maintenance, by reducing the "throw" resulting from normal angles of side planing in standard turnouts.

Mr B. W. Wilson, of Johannesburg, South Africa, observed that the work described by the Authors, as conducted under the auspices of the Track Committee in Britain, was not dissimilar to certain studies with which he had been intimately connected in South Africa. Under South African conditions, with a railway gauge of 3 feet 6 inches and curvatures as sharp as 300 feet radius, the problems of curve design were possibly a little more intricate than in Britain. Certainly the safety aspect involving considerations of overturning of vehicles on curves was vitally important. The equivalent feature under British conditions no doubt justified the omission of any mention by the Authors of a criterion of safety against overturning, but it would be interesting to know, nevertheless, the value of the appropriate factor of safety. From data collected from various sources, but chiefly from the annals of the International Railway Congresses, Mr Wilson had found 1 that world practice seemed to adhere to a minimum factor of safety of about $q=4 \cdot 0$, where $q$ denoted the number of times the moment of resistance, provided by the weight of a vehicle, exceeded the moment of overturning, provided by the centrifugal forces. On the South African Railways, values of $q$ as small as 3.0 (with flexible vehicles) were obtained on curves of certain radii on some classes of line, ${ }^{2}$ but endeavours were being made in current revisions of maximum permissible speeds to bring that figure nearer 4.0 .

A second factor, which seemed to have received rather scant consideration by the Authors, was that of economy, but there again the long mileages of single lines on the South African Railways, which had to cater for up and down traffic on a wide range of heavy gradients-traffic, moreover, with a preponderant proportion of freight services-provided conditions that were relatively more severe than in Britain and necessitated a degree of generalization in the selection of equilibrium cants which might not be desirable on the British Railways. Mr Wilson had succeeded in

I "Superelevation and Maximum Speeds on Railway Curves." Thesis pub. by University of Illinois, 1940.

2 E. M. Retief, "Applied Economics of Railway Deviations." Min. Proc. S.A. Instn Civ. Engrs, vol. 46 (1948), p. 35. Discussion by B. W. Wilson, p. 141. 
showing that, from the point of view of economy (having regard to the wear and tear on vehicle and track), the desirable value for the equilibrium speed $V_{e}$ would be given by 1 :

$$
V_{e}^{2}=\frac{\Sigma p W V^{2}}{\Sigma p W} \quad \text {. . . . . . . . . }
$$

where $p$ denoted the frequency of any train of weight $W$ and speed $V$. On the South African Railways, however, owing to the necessity for making speed concessions on ourves in favour of passenger trains, equilibrium speeds were generally higher than was prescribed by that equation. . Current practice was to determine the actual speeds of the various types of trains on representative curves of a given line, to convert those into equivalent cants, and thus derive cant-radius diagrams for trains of different categories; for example, up and down passenger trains and up and down goods on both steep and easy grades. A compromise was then necessary between the up and down trains for both passengers and goods, and finally a mean diagram for both steep and easy grades had to be determined by weighting conditions in favour of passenger trains.

The question of passenger comfort had received some attention in South Africa on rather similar lines to those described in Part I of the Paper.

A preparatory theoretical study had shown that on a flexible vehicle the horizontal centripetal acceleration acting on a passenger at maximum speed $V_{m}$ on a curve of radius $R$ could be expressed as :

$$
\ddot{y}=\frac{V_{m}^{2}-V_{e}^{2}}{R}\left[1+\frac{\sigma}{1-\sigma} \cdot \frac{H-K}{H-K_{o}}\right] . . .
$$

in which $\sigma$ denoted a factor defining the flexibility of the superstructure of the vehicle on its springs, and $H, K$, and $K_{o}$ denoted dimensions relating respectively to the heights of centre of gravity of the superstructure and the undercarriage, and to the position of the centre of oscillation. ${ }^{2} A$ typical value of $\sigma$ for a passenger coach might be of the order $0 \cdot 3$, and the ratio $\frac{H-K}{H-K_{0}}$ tended to be greater than thity, making the value of the second term within the brackets of equation (2) of the order of 0.5 . From that it would appear that the influence of the springing of a vehicle on the unbalanced radial accelerations could be important.

In 1940, Mr Wilson had initiated a series of tests to relate sensations of comfort or discomfort with values of acceleration $\ddot{y}$ and had selected for the purpose a Wickham trolley which to all intents and purposes could be

1 See reference 1, p. 564 .

2 See reference 1, p. 564. For experimental background provided by tests of overturning veltrcles on eurves, conducted in 1937, see "Derailing Tests on South African Railways." The Engineer, vol. 166, Fart 2, p. 581 (25 Nov. 1938). 
regarded as a rigid vehicle. As such, flexibility could be discounted and accelerations (in feet per second per second) legitimately computed from :

$$
\ddot{y}=\frac{V^{2}-V_{e}^{2}}{R}
$$

or

$$
\ddot{y}=2 \cdot 15 \frac{V^{2}}{r}-0.767 E \quad . \quad . \quad . \quad . \quad . \quad . \quad .
$$

where $V$ denoted the speed in miles per hour, $r$ the curve radius in feet, and $E$ the cant in inches.

A code of sensations had been adopted, based on pure judgement, as followed :

\begin{tabular}{|c|c|c|}
\hline Sensation & & Symbol \\
\hline $\begin{array}{l}\text { Very comfortable } \\
\text { Comfortable } \cdot \cdot \\
\text { Comfortable-uncomfortable } \\
\text { Uncomfortable } \\
\text { Very uncomfortable } \\
\text { Extremely uncomfortable }\end{array}$ & 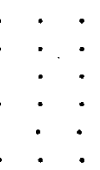 & $\begin{array}{l}\text { v.c. } \\
c . \\
c .-u . \\
u . \\
\text { v.u. } \\
\text { e.u. }\end{array}$ \\
\hline
\end{tabular}

\section{TABLe 9.-CODe of sensations}

Two trips had been made at that time on the Bethlehem-Balfour North and Nylstroom-Vaalwater lines, the trolley being run at normal cruising speeds of about 35 to 40 miles per hour with occasional variations within a range of from 30 to 50 miles per hour. Curve radii varied from $8 \frac{1}{2}$ to 43 chains on the Balfour North line and from 7 to 40 chains on the Vaalwater line.

The practice had been simply to record the sensations felt in terms of the above symbols as the trolley negotiated the curves. No attempt had been made to discriminate between transitions and circular portions of curves, but care had been exercised to discount any sudden lurches arising from faulty track alignments. Speeds of the trolley had been read direct from the recording speedometer to give values of $V$, and cants $E$ and radii $r$ had been obtained later from track records.

The computed values of $\ddot{y}$ plotted against sensation symbols were shown in Figs $18(a)$ and $18(b)$. The results, which reflected only $\mathrm{Mr}$ Wilson's observations in each case, showed considerable variance for the two lines. The disparities might have arisen from different personal perceptions of comfort on the two occasions, the standard on the Vaalwater line presumably having been conditioned by the sharp contrast between comfort and extreme discomfort, not experienced on the other line.

No further experiments had been conducted until 1947, when he and 
three other observers in a Wickham trolley had recorded their sensations on the curves of the Natal main line between Durban and Pietermaritzburg. The results were plotted in Figs 19 and, despite considerable scatter, showed a consistent trend.

\section{Figs 18}

(a)

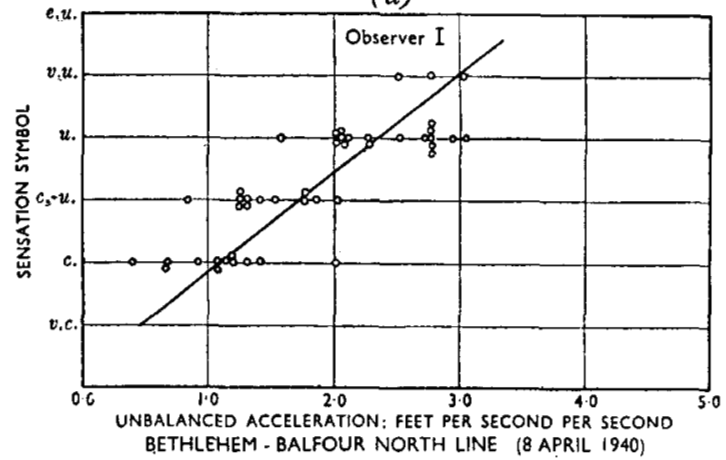

(b)

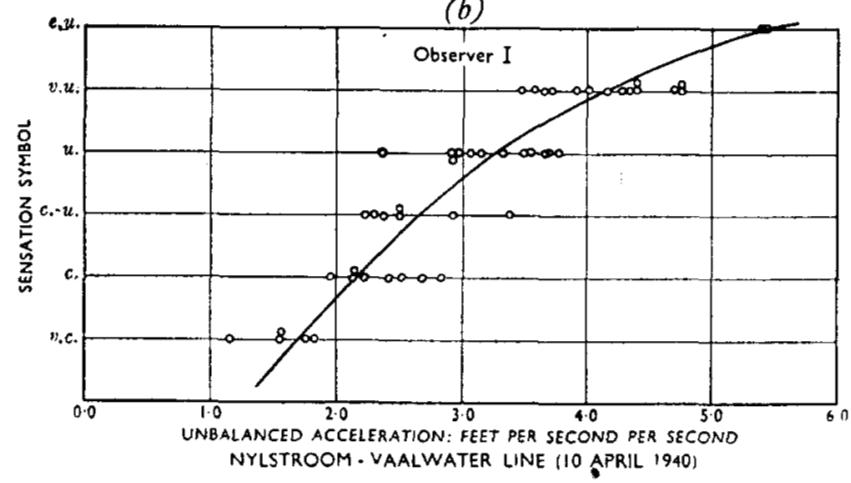

Radial Accelerations on Curves in Regation to Passenger Comfort

Taking the values of the acceleration $\ddot{y}$ where the mean lines of the diagrams intersected the borderline of discomfort $(c .-u$. $)$, the following limits to the sensation of comfort were obtained.

The demarcating radial acceleration, taken as the weighted mean of the figures in Table 10, was $2 \cdot 2$ feet per second per second, and represented an unbalanced cant on 3-foot-6-inch-gauge track of 2.9 inches. The equivalent cant deficiency on standard-gauge track would be 3.9 inches. Allowing, 


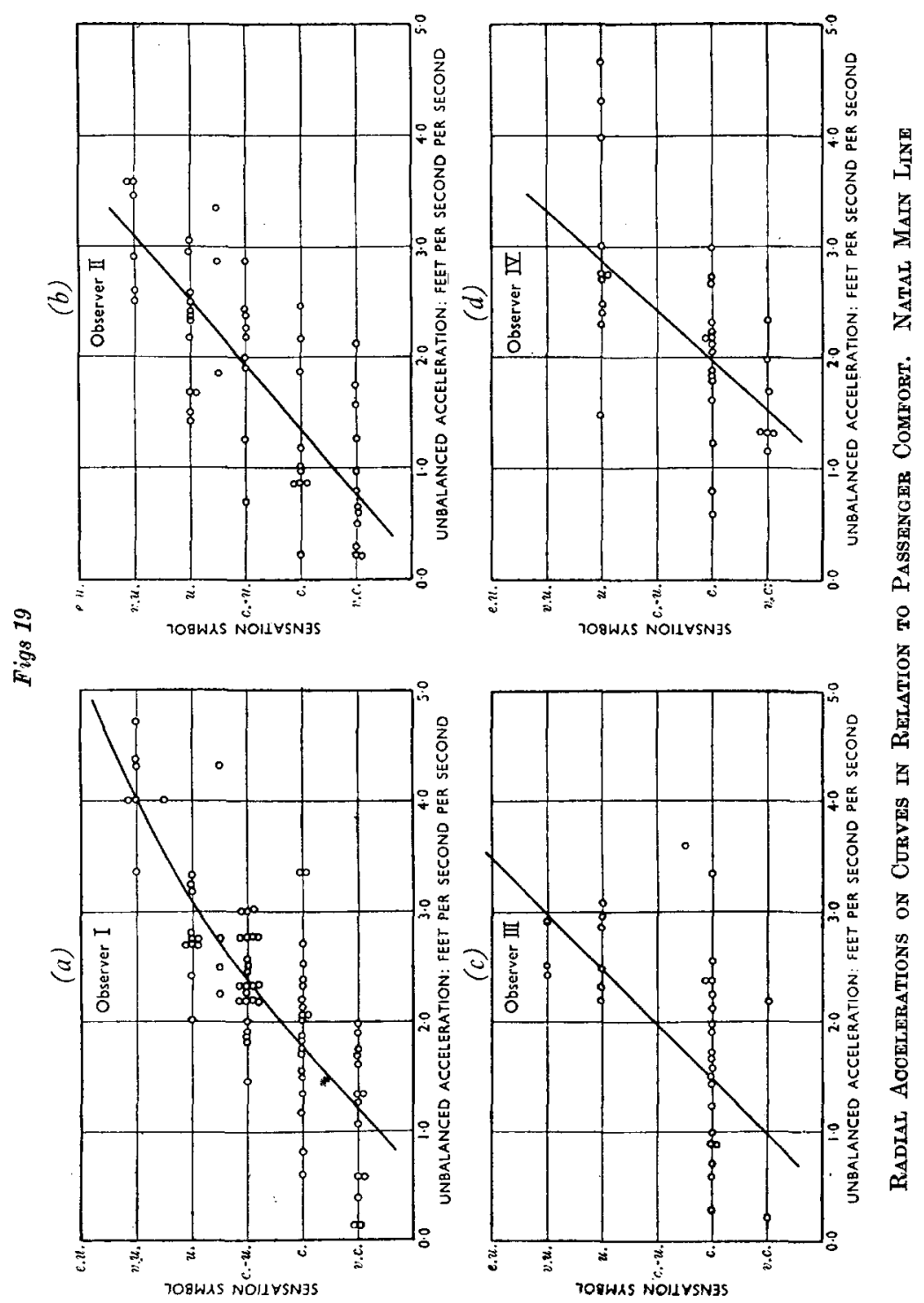




\section{TABle 10.-Limiting Radial aCCELeration For Passenger COMFORT}

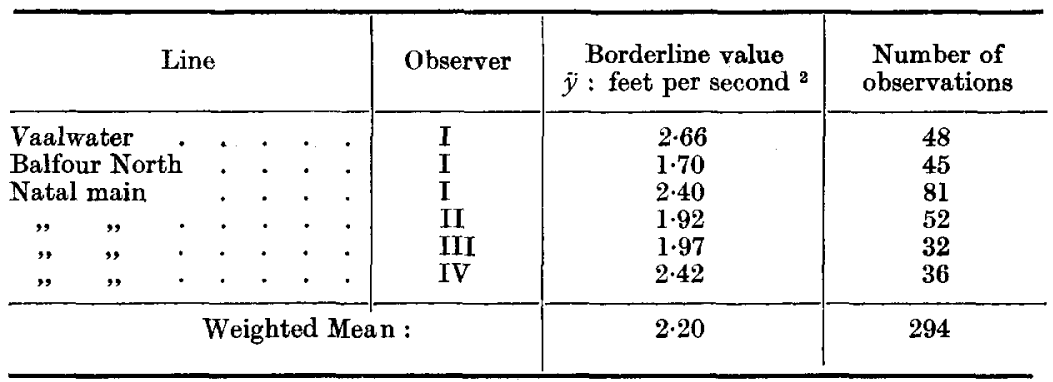

however, for the flexibility of coaching stock, equation (2) would modify (3) to

$$
\begin{aligned}
\ddot{y} & =1.5 \times 0.767(\epsilon-E) \\
& =1.1 D
\end{aligned}
$$

where $\epsilon$ denoted the cant in inches equivalent to the speed $V$, and $D(=\epsilon-E)$ denoted the cant deficiency in inches. Accordingly, for a limiting value of $\ddot{y}=\mathbf{2 \cdot 2}$ feet per second per second, the limiting cant deficiency would be about 2.6 inches for 3 -foot-6-inch gauge and 3.5 inches for a standard gauge. The latter figure agreed very well with that adopted by the British Track Committee. In South Africa, making some allowance for imperfect alignment, it had been decided to adopt a maximum cant deficiency of 2 inches. ${ }^{1}$ It might be mentioned that that figure and its equivalent for standard-gauge track were in good accord with the consensus of opinion expressed in engineering literature, ${ }^{2}$ and particularly with American railway practice, which had adopted a maximum permissible cant deficiency of 3 inches.

The necessity for adopting an empirical formula for the reduction of cant deficiency with increase of cant or reduction of radius, mentioned in Part I of the Paper, diminished considerably if the factor of safety $q$ was made a criterion as well as limiting cant deficiency $D_{m}$. That statement could perhaps best be explained by recourse to Fig. 20, in which curve $A B$ represented the maximum speeds on curves of various radii such that the factor of safety $q$ was never less than a minimum value, say $4 \cdot 0$. Curve FG was representative of overturning speeds $\left(V_{c}\right)$, which bore an approximately constant ratio to the maximum speeds. Curve DE would represent the maximum speeds that could be allowed for comfort if a cant deficiency of $D_{m}$ were not to be exceeded.

1 "Superelevations and Maximum Permissible Speeds on Curves." Research Circular No. 25.027, issued by the Office of the Chief Civil Engineer, South African Railways, 1948.

See reference 1, p. 564 . 
The actual difference between $V_{m}$ (safety) and $V_{c}$ increased considerably with radius, and travel on large-radius curves became ever safer with increase of radius because of the larger marginal speed $\left(V_{c}-V_{m}\right)$. On flat curves, overturning was thus virtually impossible and it would be quite

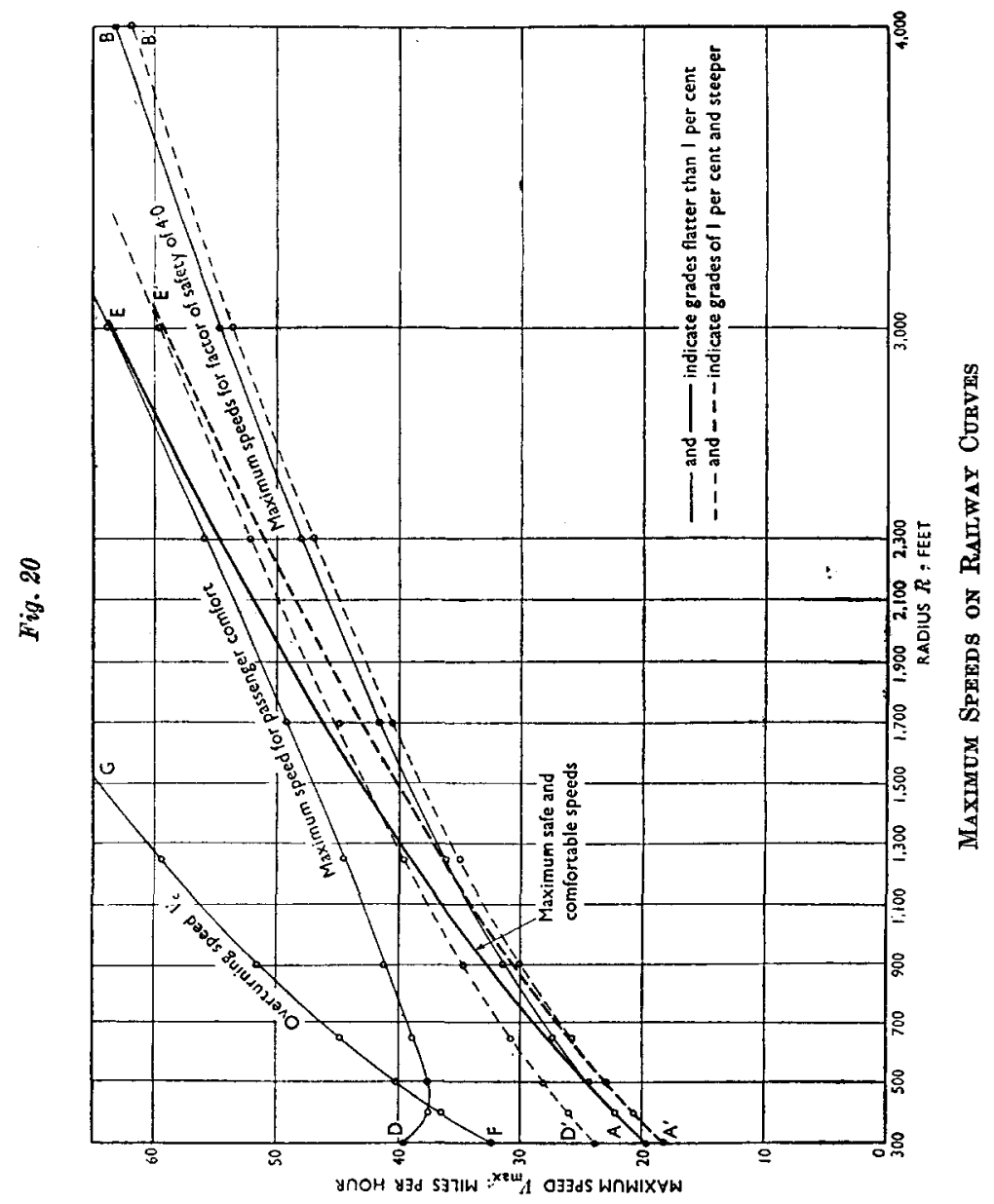

safe to allow some reduction of the factor of safety $q$ by adopting a relationship for maximum speed $V_{m}$ (safety and comfort) such as curve $A E$, which was tangential to $A B$ at $A$ and asymptotic to $D E$ at $E$. The relationship $A E$ gave the desired factor of safety on sharp curves where it was most needed and the desired comfort on flat curves: in the intermediate range the cant deficiency fell off from the maximum permissible to the extent 
that the adopted curve AE fell below DE in Fig. 20, but the gradation depended essentially upon the composite curve $\mathrm{AE}$ and the condition that it should merge with the confining curves $A B$ and $D E$. That procedure, in essence, had also been adopted in South African Railway practice. ${ }^{1}$

Mr Loach, in reply, observed that, contrary to the opinions of most others, Mr Turner had suggested that the limiting permissible steepness of cant gradient might with advantage be fixed at 1 in 200 instead of 1 in 300 , and in support of his statement he had mentioned tests with rigid-frame locomotives. Mr Loach stated that, unless the information to be gained from the tests involving locomotives on artificial cant gradients showed clearly that a gradient steeper than 1 in 300 could be tolerated, he would be reluctant to depart from the limit of 1 in 300 already agreed. It should be borne in mind that locomotives with 4-6-2 and 2-6-4 wheel arrangements might give worse conditions than a $0-8-0$, for, though the fixed wheelbase was less, the redistribution of weights on the end carrying units could be appreciable because of the unequal loading imposed on their sides by the main frame. This became important on occasions when the centering forces in the unit were also appreciable.

Mr Loach thanked Mr Wilson for his very interesting contribution; it was pleasing to learn that the thoughts of the South African engineers had developed along the same lines as those described in the Paper. It seemed to be unfortunate, however, that Mr Wilson had confined his tests to runs on a Wickham trolley, because the rather rough ride, in contrast to that in a coach, would distract attention from or possibly mask somewhat the sensations to be considered; it is suggested that the scatter of the results may be attributed to it. Afterwards $\mathrm{Mr}$ Wilson had assumed factors to take account of the springing of the vehicles, factors which might be misleading if not handled carefully. Mr Loach considered it important for sensations to be recorded in the same surroundings and comfort as normally occur in travel and so he suggested that Mr Wilson's investigation would have been more complete if, finally, tests had been made with observers sitting in a coach and experiencing all the factors normally present in travel.

Mr Maycock agreed with Mr Turner that changes of curvature, cant, and deficiency of cant should be avoided so far as possible, but that it was sometimes necessary to make such changes on main lines through junctions and that the reduction of cant might, in some cases, necessitate speed restrictions.

One was reluctant to sacrifice speed or to vary curvature and cant on main lines on account of less important trailing connexions having negative cant, but in extreme cases it might be necessary to do so. A maximum allowable amount of negative cant had not been suggested in the Paper ; all that had been said was that negative cant exceeding 3 inches at switches

1 See reference 1, p. 569 . 
and common crossings and $2 \frac{1}{2}$ inches at obtuse crossings was undesirable. It was appreciated that in certain cases a somewhat higher negative cant might be justified, but Mr Maycock considered that the use of higher amounts of negative cant should not be generally encouraged.

$\mathrm{Mr}$ Maycock appreciated the advantages to be gained by the use of the "long C, D, and $\mathbf{E}$ " switches, referred to by Mr Turner, in reducing the momentary thrust at the point of divergence and in giving a transition effect through the switches. The treatment of the subject of speeds through turnouts in the Paper had been intended, however, to provide a simple general rule applicable to standard leads and that had been based on the radius, cant, and deficiency of cant of the turnout curve without taking account of possible variations in the design of switches. Where a suitable transition of sufficient length could be provided at the entry to a diverging line a somewhat higher maximum speed could be allowed. In such a case the diverging line could be treated as a main line for the purpose of assessing maximum speed. 